\title{
Bivalve mollusk fauna and ecological groups of Unionidae and Corbiculidae families in natural and artificial reservoirs of Uzbekistan
}

\author{
$K h$. Boymurodov*, $S$. Suyarov \\ Samarkand State University, Department of Ecology, 140104 Samarkand, Uzbekistan
}

\begin{abstract}
The length of the rivers in Uzbekistan and the presence of all the biotopes in the mollusks have made they a favourable reservoir for the mollusks. However, it should be noted that all species in the rivers differ in their density. Rivers and fishery farms play a great role in formation of bivalve mollusks fauna in the canals. It was studied the fishery farms of the Syrdarya River and its surroundings have a major effect on the fauna of the Mirzachul and South Mirzachul canals; the Zarafshan River's effect on spreading of bivalve mollusks in the Dargom and Eskiankhor canals; the Amudarya River and its surrounding areas influence of fishery farms on the fauna of the Amu-Bukhara, Kizketgan and Karshi main canals. Colletopterum family breeds in the water studied, do not show any superiority in natural or artificial reservoirs compared to other breeds. Three species of these family are included in the Red Book of the Republic of Uzbekistan (C.bactrianum, C. cyreum sogdianum, C. kokandicum). C. Bactrianum can be found only in rivers in the middle Zarafshan and Amudarya, in the Syrdarya river (Syrdarya Region only), in the reservoir and in the fishery farms only in Chelak, and the canals only in the Tuyatortar and Mirzachul canals.
\end{abstract}

\section{Introduction}

The demand for biological resources of aquatic ecosystems, in particular, the demand for bivalve mollusks, is increasing year by year worldwide. Especially, nowadays there are 13588.2 million tons of food raw materials, as well as grown pearls amounting to 5.9 million USD (according to http://missjoaquim.com/southseapearls/blog/indonesian-pearlsin-figures) and the bivalve mollusks which are used in pond water treatment systems in developed countries (according to GE's Water \& Process Technologies (www.gewater.com). It is important to determine the species composition and possible use of Unionidae and Corbisulidae families, especially those that have a special role in freshwater distribution, especially among bivalve clams. Conducting studies on distribution of representatives of this family, their population status and their use in economic sectors is as follows: identification of species composition of Unionidae and Corbisulidae family species in the zoogeographic or administrative areas; justification of the possibility of their

\footnotetext{
*Corresponding author: Boymurodov1971@mail.ru
} 
distribution in all natural and artificial reservoirs; the role of bivalve mollusks as invasive dispersal organisms; and as one of the most valuable problems is the identification of organism and population performance of bivalve mollusks in different types of reservoirs.

Regional species composition of bivalve mollusks, their distribution, systematization, scientific works on their protection were conducted by foreign scientists such as James H.Thorp., Alanp Covich; Aldridge; Bouchet; Huber Markus; Bogan; Annabelle Cuttelod and others and research studies on pearls production in the economic sectors, and especially in artificial reservoirs, were conducted by scientists like Maria Haws; Mamangkey and others; Rahayu and others; Sata Yoshida, Srie Rahayu and others.

We can observe research studies on the determination of territorial diversity, taxonomic structure and signs of variability in bivalve mollusks in the CIS countries in the works of scientists like Bogatov, Starobogatov; Bogatov; Andreev and others; population status assessment and global invasive species distribution studies were conducted by Alekhina and others; Panov and others; Son; Yanovich]; some research studies on the importance of two-stage clams in determining water pollution levels can be noted among the works of the scientists like Rijinashvili A.L., Sintyurina A.V., Bigaliev A.B., Kuzmenkin D.V.

It is noteworthy that there is insufficient information on the distribution, morphology and resources of the bivalve mollusks in various reservoirs in the Republic. I.Z. Izzatullaev's research work reveals some information about certain species in some water reservoirs of Uzbekistan. These data do not provide sufficient scientific evidence for the complete species tracking and distribution of ecosystems of Unionidae and Corbisulidae species within the marine macrobentos.

Bivalve mollusks are an important element of the food chain in water biocenosis. Numerous young and old bivalve mollusks are considered to be fodder for fish, waterfowl and geese. The main food for fish in the Caspian Sea is dreissens. $42.2 \%$ of Caspian roach's food, and 17\% of Carp's food consists of mollusks. At the same time, small clams are the main food for breams and sturgeons. Large fish are fed by relatively large mollusks. For instance, when carp reaches $65-120 \mathrm{~mm}$ of length it can eat 5-8.5 mm bivalve mollusks. In aquatic ecosystems, unionides from bivalve mollusks migrate as parasites to fish being in larvae phase. Many sea creatures act as intermediate hosts for trematodes [1,2].

The practical use of bivalve mollusks is important in determining the levels of organic (saprobial) and radioactive contamination of water in the field of production, especially in nature protection, and also for the cultivation of cultural pearls. Although $70 \%$ of the world is covered by water, freshwater accounts for only $3 \%$ of the total water resources. However, more than $80 \%$ of freshwater cannot be used by biota organisms. Today, the use of fresh water is a major problem for humanity - all kinds of human activities cause contamination of water.

Water is being increasingly used in population growth and industrialization of the community, which also results in a natural slowdown in the purification of water sources and resources by itself $[3,4,5]$

The main source of contaminants in water ecosystems is industrial and industrial wastewater. Measures to completely remove contaminated water do not always allow the complete purification of the organic and inorganic contaminants contained in the water. Accordingly, biological control over the quality of natural and purified industrial water is one of the most vulnerable problems, with the use of bioindication methods being a reliable indicator for the assessment of environmental conditions in hydro systems. The main zoobenthos in hydrosystems are mollusks and oligochetes with a high life expectancy group. Their lifespan is approximately 6 years, and they also contain a large proportion of zoobenthos biomass in ponds and streams.

Such kind of long-living and high biomass components is the best indicator of continuous pollution of ecosystems. In the formation and structure of zoobenthos, several 
methods of bioindication are proposed in the following directions: species-indicators of saprobial calculation of biotic indices for large taxons - oligochetes, crustaceans, chromonomides, mollusks; it should be noted that it is of great importance to assess the level of diversity $[2,6,7]$.

In this context, the determination of wetlands species-specific indicators is one of the indicators contributing to the comprehensive assessment of the water environment.

It is important to take inventory of bivalve mollusks of all kinds (natural and artificial) in Uzbekistan's watersheds and water reservoirs, determine their distribution patterns in the watersheds, assess the current state of rare and endemic species populations, and study their prospects for economic use.

\section{Materials and methods of study}

The study of bivalve mollusks and collecting material from the river basins in Uzbekistan began in 2004. The species composition, ecological features, inter-biotopic distribution and significance of bivalve mollusks in the river basins have not been studied sufficiently so far.

Materials for the study were collected in the spring, summer and autumn of the years of 2004-2019 from the following river basins in Uzbekistan; the rivers: the Amudarya river, the Sirdarya river, the Kashkadarya river, the Surkhandarya river, the Zarafshan river, the Akdarya river, and Koradaryo river; water reservoirs: Tuytamuyin, Uchkizil, Kattakurgan, Akdarya, Tusinoy, Tallimarjon, Chimkurgan, Pachkamar, South Surkhan, Shurkul; seas: Aydarkul and Ashikul fishery farms and from the streams, canals and ditches leading to these farms.

In addition, the materials, used in the research, which were collected from 1990 to 2018 at the Samarkand State University's Department of Ecology and Nature Conservation, were also target of the study.

A total of 10,421 sites were studied, where 3,832 mollusks habitats were found. Specimens of this mollusk were studied by the methods of large systematic works suggested by Plohinsky in 1970; Rijinashvili in 2005; Starobogatov, Izzatullaev in 1984, Izzatullaev, Boymurodov in 2010 [8].

\section{Results of the study.}

Due to the natural and geographically moderate and arid zone of the country, Uzbekistan has an uneven distribution of precipitation over the year and seasons. This state of affairs also influences the changing hydrological regime of natural and man-made reservoirs rivers, lakes, fisheries, reservoirs and canals. As long as the life of bivalve mollusks in freshwater ponds is associated with a constant water environment, such acute hydrological regimes in the watersheds are one of the factors controlling their number and quantity.

We can say from the distribution of bivalve mollusks in the reservoirs of Uzbekistan, the Unionidae and Corbiculidae families, that it is characteristic of the distribution of mollusks in water bodies not paying attention to their density (Fig. 1). We can say that the rivers are a fairly distributed pond for all the breeds - where all of the breeds are found to be close $(23-27 \%)$. The length of the rivers and the presence of all the biotopes in which the mollusks reside have made the reservoir a favorable reservoir for the mollusks. However, it should be noted that all species in the rivers differ in their density. For instance, although Sinanodonta family representatives are found in rivers, their density in rivers is lower than in other watersheds. Rivers are the most favorable watershed for Corbiculina family species to reproduce and spread. In rivers, it reaches the maximum density of the breeds (for instance, Corbiculina tibetensis - the Middle Zarafshan, $4.4 / \mathrm{m}^{2}$; Corbiculina ferghanensis - 
the Middle Amudarya - 4.2/ $\mathrm{m}^{2}$ ).
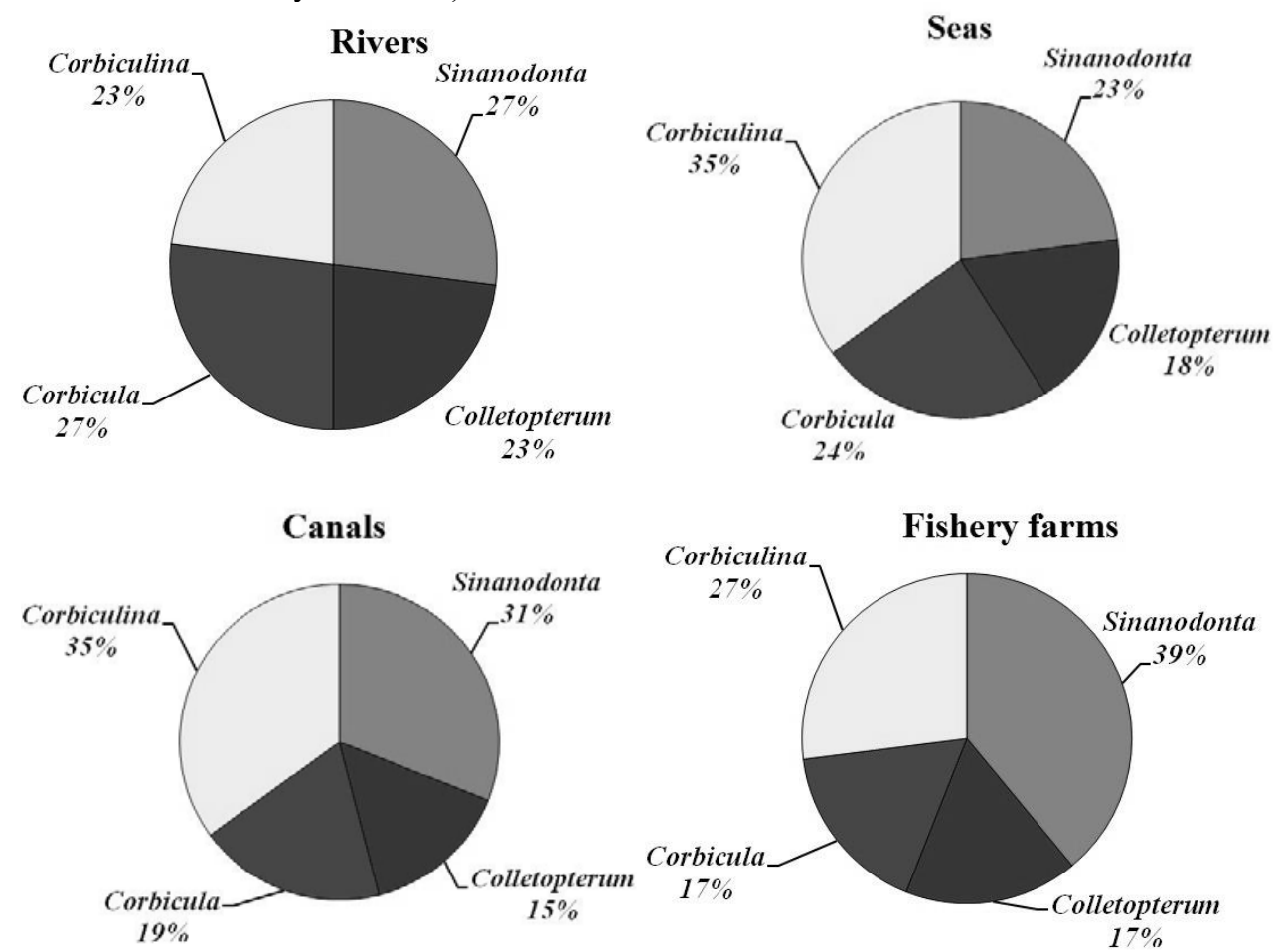

Water reservoirs

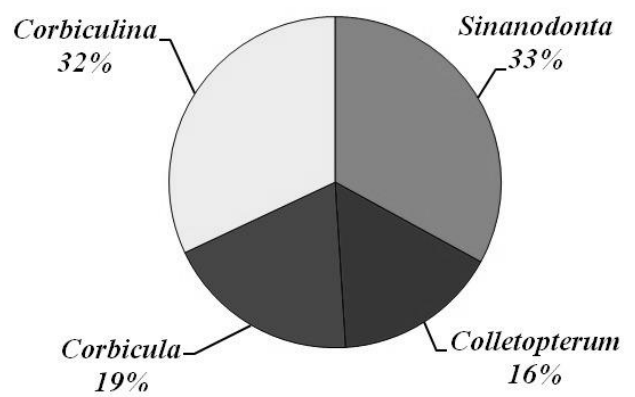

Fig. 1. Distribution of bivalve mollusks breeds in the reservoirs of the Unionidae, Corbisulidae family, in \%.

Although Uzbekistan's natural lakes (Aydarkul, Ashikul) are an indoor pond, Sinanodonta family breeds are not common in clay biotopes. Especially in the Lower Amudarya river, the absence of these breeds in Ashikul resulted in their low percentage. We can even estimate that the relative density coefficients of the common Sinanodonta family breeds are down to 0.2 in some channels and this conditions may have a negative effect on the growth of mollusks. The water flow rate in the canals, their constant use as an irrigation system, and their isolation (e.g. cementation of the bottom) to prevent water loss in the canals will result in a dramatic change in the hydrological regime of the canals. Taking into account the fact that the benthos, the bivalve mollusks, are more closely related to the wetlands and peaceful reservoirs, the above-mentioned factors have a major negative 
impact on them. Positive effects on the number of species in the bivalve mollusks can be mentioned as in the canals can be attributed to their ancient, wetland (Dargom) and their length (Eskianhor), and their relation to fishery farms (Dargom, Mirzachul).

Colletopterum family breeds - like Colletopterum bactrianum, Colletopterum cyreum sogdianum, Colletopterum ponderosum volgense, Colletopterum kokandicum in the water studied, do not show any superiority in natural or artificial reservoirs compared to other breeds. Three species of these family are included in the Red Book of the Republic of Uzbekistan (C.bactrianum, C. cyreum sogdianum, C. kokandicum) C. Bactrianum can be found only in rivers in the middle Zarafshan and Amudarya, in the Syrdarya river (Syrdarya Region only), in the reservoir and in the fishery farms only in Chelak, and the canals only in the Tuyatortar and Mirzachul canals.

Although C. cyreum sogdianum is included in the Red Book (2009), it is now among the most common mollusks. In general, there are favorable biotopes in the breeding farms for the representatives of the Colletopterum breed - where the maximum breed density is observed.

Representatives of the Corbicula breed, as well as the representatives of the Colletopterum breed, do not show any superiority in the natural and artificial reservoirs compared to those of other breeds. All of them (Corbicula cor, Corbicula purpurea, Corbicula fluminalis) are rare species. Their maximum density is observed in river basins (C. cor - the Middle Kashkadarya, $2.7 / \mathrm{m}^{2}$, C. purpurea, C. fluminalis - the Middle Zarafshan, 2.3-2.5/ $\mathrm{m}^{2}$ ).

The distribution of bivalve mollusks by ecological groups is common in the water bodies of Uzbekistan (Fig. 2). The peloreophilic environmental group predominates in all watersheds, but the species included in the ecological group are diverse in different watersheds.
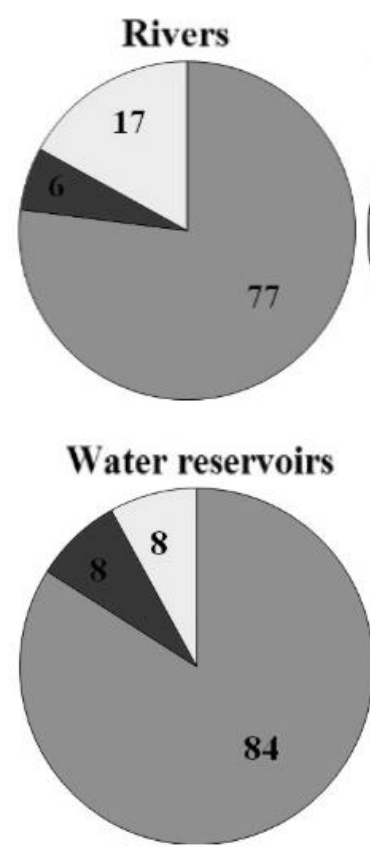
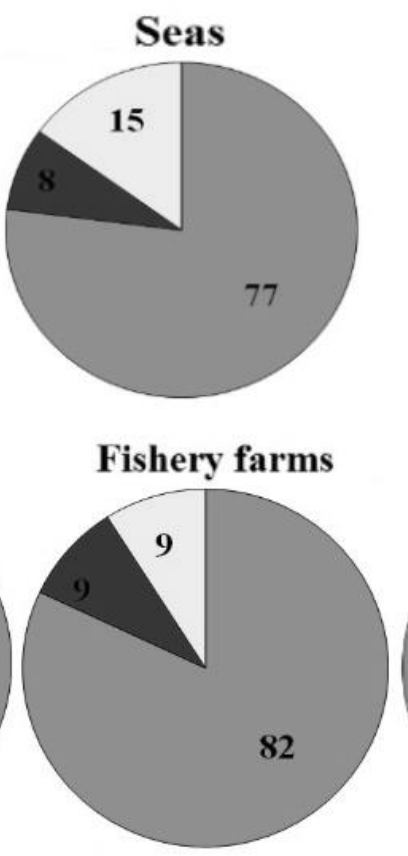

\section{$\square$ pelereophil} a pelelemnofil

$\square$ rheophil

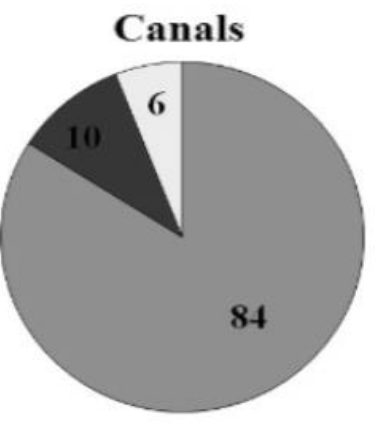

Fig. 2. Distribution of bivalve mollusks in Uzbekistan by ecological groups, in \%

Sinanodonta gibba, S. orbicularis, Corbiculina tibetensis and C. ferghanensis dominate the group from peloreophiles in rivers, fisheries and reservoirs. The dominance of the 
channels is attributed to Corbiculina tibetensis and C. ferghanensis. The next most common environmental group in water bodies is the reophils.

Colletopterum bactrianum and $S$. cyreum sogdianum but not $S$. cyreum sogdianum are found to be predominant in many water ponds. Pelolimnophils are extremely rare in water bodies and their parts. In the middle of the $20^{\text {th }}$ century, anthropogenic disturbances of landbased zoogeographical barriers have led to the invasion of many species that have remained unchanged for a long time, including invasive species in the hydrophobia. As a result, the species is still extending. In this respect, mollusks are especially important in the distribution and adaptation of terrestrial invasive species. It should be noted that the bivalve mollusk, Sinanodonta woodiana, is an invasive species for the northern regions of the Eurasian continent. This species was first discovered in the Romanian fisheries in 1979 in Europe and has been widely used in Romanian water ecosystems for 20 years. The species has now been established throughout 19 European countries, creating stable populations throughout Europe.

It should be noted here that the changes in natural hydrological systems as a result of hydrotechnical structures and anthropogenic impacts are one of the main factors influencing the diversity and invasion of the bivalve mollusk fauna. For example, the construction of large transboundary canals (the Dnepr - the North Donetsk and Volga-on-Don), formed by hydrographic links between the Central and Northern European invasion corridors, led to the exposition of many mollusks, including Sinanodonta woodia, from the Middle Dnepr to the Don and the Volga rivers.

There is no evidence that Sinanodonta woodiana, which is most likely to come with fish, is present or dispersed in the southern regions of Central Asia, particularly in Uzbekistan. If we look at the natural range of Sinanodonta woodia, its range lies mainly in the northern regions - Korea, China, Japan, and the Far East of Russia (the Amur Basin and Primoria Plains). According to the data, Sinanodonta woodiana is more susceptible to colder regions than hot areas, and is able to lay eggs even when the water temperature is 7$10^{\circ} \mathrm{C}$. The same temperature factor serves as a limiting factor for the distribution of this species in the northern regions of Eurasia but not from the south of the continent.

Temperature as a limiting factor for bivalve mollusks can also be seen in other Sinanodonta breeds - Chinese toothless S.orbicularis, S. Gibba, and S. puerorum in the study. The natural range of these species is south of the Sinanodonta woodiana range - the Yantzhi and Juanxi River rivers in China. According to literary analysis (Catalog, European Book) these three species, on the contrary, are not found in the northern regions of the Eurasian continent (Russia, all parts of Europe). However, in the south of Central Asia, this species can be said to be the most common and high-density species in all water bodies.

Representatives of the Sinanodonta breed have been inadvertently introduced to Chinese climatic fish (Ctenopharyngodon idella, Hypophthalmichthys molitrix) since the 1980 s and have been a successful introduction to the country's climate. Successful distribution of these breeds in the water bodies of Uzbekistan is important not only for climatic factors (temperature) but also for fish farms from artificial reservoirs. Research has shown that fisheries play an important role not only in the distribution of mollusks, but also in their conservation. In particular, the presence of these species in the unfavorable downstream areas of many river basins (the Lower Amudarya and the Lower Zarafshan), but the presence of farms contributes to the conservation of the species population. The presence of the largest density of these breeds in fishery farms indicates the importance of fisheries for the Sinanodonta family breeds. 


\section{Conclusion}

The length of the rivers in Uzbekistan and the presence of all the biotopes in the mollusks have made the reservoir a favorable reservoir for the mollusks. However, it should be noted that all species in the rivers differ in their density. Rivers and fishery farms play a great role in formation of bivalve mollusks fauna in the canals. It was found out and studied that the fishery farms of the Syrdarya River and its surroundings have a major effect on the fauna of the Mirzachul and South Mirzachul canals; the Zarafshan River's effect on spreading of bivalve mollusks in the Dargom and Eskiankhor canals; the Amudarya River and its surrounding areas influence of fishery farms on the fauna of the Amu-Bukhara, Kizketgan and Karshi main canals.

\section{References}

1. M.O. Son, Mollusks invaders in the fresh and brackish waters of the Northern Black Sea (Odessa, 2007).

2. L. N. Yanovich, M. M. Pampura, Uzhgorod University Scientific Bulletin Biology Series, 32, 145-149 (2012)

3. O. P. Popa, Aquatic Invasions, 2(3), 265-267 (2007)

4. D. D. Danilin, Mollusks of the Eastern Asia and Adjacent Seas: Abstracts the conf. (October 6-8, 2014, Vladivostok, Russia), 12-13 (Dalnauka, Vladivostok, 2014)

5. M. Huber, Compendium of Bivalves. A Full-color Guide to 3,300 of the Worlds Marine Bivalves. A Status on Bivalvia after 250 Y ears of Research (ConchBooks, 2010)

6. Z.I. Izzatullaev, Bul. of the Zhitomir Pedagogical Univ., 2, 21-23 (2002)

7. L.N. Yanovich, Reports of the National Academy of Sciences of Ukraine, 6, 158-163, (2010)

8. Kh.T. Boymurodov, East. Eur. Sc. J., 4, 44-47 (2015) 